\title{
Clinical Predictors of EMG-confirmed Cervical and Lumbosacral Radiculopathy
}

\author{
Ali Hassan, Bilal Hameed, Muhammad Islam, Bhojo Khealani, Mustafa Khan, \\ Saad Shafqat
}

\begin{abstract}
Background: Electromyography (EMG) for suspected cervical or lumbosacral root compression is often negative, producing expense and physical discomfort that could have been avoided. To improve patient selection for testing, we sought to identify clinical features that would accurately predict presence of radiculopathy on EMG. Methods: Adult patients consecutively evaluated for suspected cervical or lumbosacral root compression at an academic clinical neurophysiology laboratory were prospectively enrolled. Presence of clinical features suggesting root disease (neck or back pain, dermatomal pain or numbness, myotomal weakness, segmental reflex loss, and straight leg-raising) was recorded prior to testing. EMG examination to confirm root compression was conducted per standard protocols. Analysis was based on computation of sensitivity, specificity, predictive values, and accuracy. Results: A total of 200 patients (55\% male; mean age 46.4 years; $38 \%$ suspected of cervical and 62\% of lumbosacral disease) were included. EMG evidence of root disease was detected in $31 \%$ of cervical and $62 \%$ of lumbosacral referrals. Dermatomal pain was the most sensitive, and segmental reflex loss and myotomal weakness the most specific individual predictors of root disease. Combined presence of dermatomal pain or numbness with segmental reflex loss and myotomal weakness approached specificities of $78 \%$ (lumbosacral disease) and $99 \%$ (cervical disease). In all cases, myotomal weakness was the most accurate predictor of root disease. Conclusion: The diverse symptoms and signs of cervical and lumbosacral root compression predict a positive electrodiagnosis of radiculopathy with varying degrees of accuracy, and may be used to guide patient selection for EMG testing.
\end{abstract}

RÉSUMÉ: Facteurs de prédiction cliniques de la radiculopathie cervicale et lombo-sacrée confirmée par EMG. Contexte : L'électromyogramme (EMG) effectué lorsque l'on soupçonne une compression radiculaire cervicale ou lombo-sacrée est souvent négatif, ce qui engendre des coûts et un inconfort qui pourraient être évités. Nous avons voulu identifier les caractéristiques cliniques qui prédisent de façon fiable la présence d'une radiculopathie à l'EMG afin d'améliorer la sélection des patients soumis à ce test. Méthode : Des patients adultes évalués de façon consécutive, chez qui on soupçonnait une compression radiculaire cervicale ou lombo-sacrée dans un laboratoire de neurophysiologie clinique en milieu universitaire, ont été recrutés de façon prospective. La présence de manifestations cliniques suggérant une maladie radiculaire (douleur cervicale ou dorsale, douleur ou engourdissement au niveau d'un dermatome, faiblesse au niveau d'un myotome, perte de réflexe segmentaire et de soulèvement de la jambe en extension) a été noté avant le test. L'EMG effectué pour confirmer la compression radiculaire a été effectué selon le protocole standard. L'analyse visait à déterminer la sensibilité, la spécificité, la valeur prédictive et l'exactitude du test. Résultats : Deux cent patients dont l'âge moyen était de 46,4 ans (55\% d'hommes; maladie cervicale soupçonnée chez $38 \%$ et lombo-sacrée chez $62 \%$ ) ont été inclus dans l'étude. Des signes de maladie radiculaire ont été notés chez $31 \%$ des patients référés pour une pathologie cervicale et chez $62 \%$ de ceux référés pour une pathologie lombo-sacrée. La douleur au niveau d'un dermatome était le symptôme le plus sensible et la perte de réflexe segmentaire et la faiblesse au niveau d'un myotome étaient les facteurs individuels de prédiction les plus spécifiques de la maladie radiculaire. La présence combinée de douleur ou d'engourdissement au niveau d'un dermatome, avec une perte de réflexe segmentaire et une faiblesse au niveau d'un myotome avaient une spécificité de près de $78 \%$ pour la maladie lombo-sacrée et de près de $99 \%$ pour la maladie cervicale. Chez tous les cas, la faiblesse au niveau d'un myotome était le facteur de prédiction le plus exact de la maladie radiculaire. Conclusion : Les divers symptômes et signes de compression radiculaire cervicale et lombo-sacrée prédisent un électrodiagnostic positif de radiculopathie avec un degré variable d'exactitude et peuvent être utilisés pour guider le choix des patients soumis à un EMG.

Can J Neurol Sci. 2013; 40: 219-224

Since its initial description in $1934^{1}$, the syndrome of spinal root compression has been recognized as a frequent presentation in neurological practice. Dermatomal pain and numbness are the characteristic complaints; in advanced disease, these may be associated with segmental reflex loss, with or without myotomal weakness. Cervical and lumbosacral roots are the most commonly affected, with peak involvement seen at L4-L5 and L5-S1 levels in the lumbosacral region ${ }^{2}$, and at C5-C6 and C6$\mathrm{C} 7$ levels in the cervical region ${ }^{3}$. Overall, root compression occurs more often in the lumbosacral rather than the cervical region, with lumbosacral cases comprising $62 \%$ to $90 \%$, and cervical cases $5 \%$ to $36 \%$, of all radiculopathies ${ }^{1}$.

From the Section of Neurology, Department of Medicine, Aga Khan University Medical College, Karachi, Pakistan.

Received April 29, 2011. Final Revisions Submitted September 6, 2012. Correspondence to: Saad Shafqat, Aga Khan University, Stadium Road, Karachi 74800, Pakistan.Email: saad.shafqat@aku.edu. 
Electrophysiological assessment through nerve conduction studies (NCS) and needle electromyography(EMG) is an important part of the diagnostic evaluation, serving as a confirmatory supplement to history and physical examination ${ }^{4}$. Electrodiagnosis can establish the presence of radiculopathy, identify the implicated spinal $\operatorname{root}(\mathrm{s})$, grade the severity of involvement, and exclude other entities in the differential diagnosis; it can also distinguish acute and active root involvement from chronic or quiescent pathology. Electrodiagnosis is especially valuable in situations where neuro-imaging studies are equivocal, and as a pre-requisite to consideration of surgical intervention ${ }^{1-3}$. According to evidencebased guidelines developed by the American Association of Neuromuscular and Electrodiagnostic Medicine, electromyography is a valuable tool in the diagnosis of both cervical ${ }^{5}$ as well as lumbosacral radiculopathy ${ }^{6}$. Despite these advantages, electrodiagnosis in this setting is also associated with certain drawbacks, including limited sensitivity, as well as time, expense, and a degree of physical discomfort for the patient ${ }^{7}$. Although suspected radiculopathy is one of the commonest reasons for referral to an electrodiagnostic laboratory, systematic data examining the correlation between clinical assessment and EMG positivity are sparse. Improving the yield of electrodiagnosis in this population through better patient selection and referral would therefore be beneficial.

To this end, we tested the hypothesis that specific clinical findings obtained through history and physical examination can predict electrodiagnostic abnormality in cases of suspected radiculopathy. The overall aim was to develop a means of improving test yield, in the hope of minimizing negative tests. Although electromyographers often say that a normal clinical examination predicts normal electrodiagnostic findings, the statistical value of discrete symptoms and signs awaits better definition. In this study, we evaluated the ability of a range of symptoms (dermatomal pain, dermatomal numbness, radiating neck pain, and localized or radiating back pain) along with signs (dermatomal sensory loss, segmental reflex loss, myotomal weakness, and inhibited straight-leg raising) in predicting electrodiagnostically confirmed cervical or lumbosacral root compression with sensitivity, specificity, and accuracy.

\section{Methods}

This is a prospective cross-sectional study of 200 adult patients consecutively referred with clinical suspicion of cervical or lumbosacral radiculopathy to an academic clinical neurophysiology laboratory over a ten month period. The bulk of referrals came from neurologists, neurosurgeons, and orthopedic surgeons, with occasional referrals from internists and general practitioners. The prevalence of specific symptoms and signs in this referral population were compared with the prevalence of abnormal electrodiagnostic findings obtained through testing. This study focused exclusively on clinical evaluation and electrodiagnostic results; neuroimaging was not included.

\section{Patients}

All patients underwent a complete history, general physical examination, and neurological examination. Based on the known clinical characteristics of spinal root compression ${ }^{1-3}$, three symptoms and three signs for cervical radiculopathy, and three symptoms and four signs for lumbosacral radiculopathy, were selected as clinical predictors. In the cervical region, symptoms included dermatomal pain, abnormal dermatomal sensation (numbness and/or paresthesias), and neck pain radiating into the upper $\operatorname{limb}(\mathrm{s})$; while the signs were myotomal muscle weakness, segmental reflex loss, and dermatomal sensory loss. In the lumbosacral region, symptoms included dermatomal pain, abnormal dermatomal sensation (numbness and/or paresthesias), and back pain radiating into the lower $\operatorname{limb}(\mathrm{s})$; while the signs were the same as in the cervical region, with the addition of straight-leg raising (SLR).

All evaluation and testing was performed by two EMG fellows, under supervision of a trained electromyographer. One fellow obtained the history and performed the clinical examination, while the other conducted electrodiagnostic testing blinded to the clinical examination findings; fellows took turns in these activities, alternating roles with each new enrolment. Both EMG fellows had completed a neurology residency; one of them had also cleared Pakistan's terminal qualifying examination in neurology (Fellowship of the College of Physicians and Surgeons), while the other was waiting to appear. Dermatomal sensory loss was defined as reduced pinprick sensation that maps to a dermatomal distribution, ipsilateral to the symptomatic side. Segmental reflex loss was defined as a deep-tendon reflex response ipsilateral to the symptomatic side that was either absent, or asymmetrically reduced compared with the opposite side. Myotomal weakness was defined as any detectable weakness in a myotomal distribution, ipsliateral to the symptomatic side.

\section{Electrodiagnostic testing}

A standard nerve conduction measurement along with concentric needle EMG examination was performed on each patient. For cases of suspected cervical radiculopathy, the study consisted of (a) nerve conduction assessment in two motor and two sensory nerves in the upper limb on the affected side, and (b) needle examination of at least two muscles from each root (C5C8) along with cervical paraspinal muscles (in the absence of prior neck surgery) on the affected side. For cases of suspected lumbosacral radiculopathy, the study consisted of (a) nerve conduction assessment in two motor nerves on the affected side along with bilateral sural nerves and bilateral testing for $\mathrm{H}$ reflex, and (b) needle examination of at least two muscles (one distal and one proximal, where possible) from each root (L2-S1) along with lumbosacral paraspinal muscles (in the absence of prior back surgery) on the affected side.

For both cervical as well as lumbosacral cases, needle study followed a standardized root screen based on highyield muscles ${ }^{8,9}$, with sampling of additional muscles at the electromyographer's judgment. Electrodiagnosis of radiculopathy ${ }^{10}$ was based on the presence of active denervation (fibrillation potentials and/or positive sharp waves) and/or chronic denervation-renervation (neurogenic motor unit potentials with high amplitude and broad duration), or reduced motor unit recruitment (in cases with a history of symptoms $<3$ weeks), in two or more muscles belonging to the same myotome but innervated by different peripheral nerves. Active denervation in paraspinal muscles was considered a supplement to the limb 
Table 1: Clinical features in the study population

\begin{tabular}{lcc}
\hline Clinical Features & Cervical region $(\mathrm{N}=77)$ & Lumbosacral region $(\mathrm{N}=123)$ \\
\hline Symptoms & $23(29.9 \%)$ & $55(44.7 \%)$ \\
Abnormal dermatomal sensation & $28(36.4 \%)$ & $66(53.7 \%)$ \\
Dermatomal pain & $50(64.9 \%)$ & - \\
Radiatign neck pain & - & $71(57.7 \%)$ \\
Radiating back pain & $17(22.1 \%)$ & $28(22.8 \%)$ \\
\hline Signs & $12(15.6 \%)$ & $34(27.6 \%)$ \\
Myotomal weakness & $05(6.5 \%)$ & $56(45.5 \%)$ \\
Dermatomal sensory loss & - & $29(23.6 \%)$ \\
Segmental reflex loss & & \\
Positive SLR ${ }^{*}$ test &
\end{tabular}

SLR, straight-leg raising

findings; its presence alone was insufficient for diagnosing radiculopathy, nor was it required for the diagnosis.

\section{Data analysis}

The Statistical Package for Social Sciences (SPSS, version 17.0) was used for data analysis. Descriptive analysis was done for demographic and clinical features; results are presented as mean \pm standard deviation or range for quantitative variables, and number (percentage) for qualitative variables. Sensitivity, specificity, negative predictive value, and positive predictive value of clinical signs and symptoms (along with 95\% confidence intervals) were calculated by cross-tabulation with electrodiagnostic findings using a standard 2X2 table. In addition, a composite measure of accuracy - mathematically defined as the percentage of true results (sum of true positives and true negatives) from a denominator of all results (sum of true and false positives and true and false negatives) - was also computed $^{11}$.

\section{Results}

A total of 200 patients were included in the study, of which $111(55.5 \%)$ were male. Mean ( \pm SD) age was $46.4 \pm 14.6$ years (range 16-86 years). At the time of referral, cervical radiculopathy was suspected in $77(38.5 \%)$ patients and lumbosacral radiculopathy was suspected in $123(61.5 \%)$ patients. Yield of electrodiagnostically-confirmed radiculopathy was 30\% (23 patients) in cervical referrals, and 58.5\% (72 patients) in lumbosacral referrals.

\section{Cervical cases}

Among the 77 patients referred with cervical complaints, females (39 patients, $51 \%$ ) and males (38 patients, $49 \%$ ) were equally represented. Mean $( \pm \mathrm{SD})$ age was $42.9 \pm 13.2$ years (range 16-80 years). In 39 patients (50\%), the referral indication was cervical radiculopathy alone, while indications for the remaining cases included carpal tunnel syndrome (30 patients), brachial plexopathy (7 patients), and ulnar neuropathy at the elbow (1 patient), in addition to cervical radiculopathy. Electrophysiological diagnosis was cervical radiculopathy in 23 patients $(30 \%)$, other electrodiagnostic abnormality in 24 patients $(31 \%)$, and normal in 30 patients (39\%). The 23 cases of confirmed cervical radiculopathy included ten patients with root localization at $\mathrm{C} 5-\mathrm{C} 6$, three with C6-C7, five with $\mathrm{C} 7$, two with C7-C8, and three with C8-T1 (abnormality in overlapping myotomes implies that further localization was unclear). The remaining electrodiagnostically abnormal cases included 20 patients with carpal tunnel syndrome; one patient each with peripheral neuropathy, ulnar neuropathy at the elbow, and brachial plexopathy involving the medial cord; and one indeterminate case in whom active denervation was limited to paraspinal muscles alone.

\section{Lumbosacral cases}

Of the 123 patients with lumbosacral complaints, males were more prevalent, comprising 59\% (73 patients), with $41 \%$ females (50 patients). Mean $( \pm$ SD) age was $48.4 \pm 10.5$ years (range 16-86 years). In 98 patients (78\%) the referral indication was lumbosacral radiculopathy alone, while indications for the remaining cases included peripheral neuropathy (17 patients), peroneal neuropathy (3 patients), meralgia paresthetica (3 patients), lumbosacral plexopathy (1 patient), and myopathy (1 patient), in addition to lumbosacral radiculopathy. Electrophysiological diagnosis was lumbosacral radiculopathy in 72 patients $(58.5 \%)$, other electrodiagnostic abnormality in 16 patients $(13 \%)$, and normal in 35 patients $(28 \%)$. The 72 cases of confirmed lumbosacral radiculopathy included 7 patients with root localization at L2-L4, 4 with L4-L5, 13 with L5, 36 with L5-S1, and 12 with S1 (abnormality in overlapping myotomes implies that further localization was unclear). The remaining electrodiagnostically abnormal cases included six patients with peripheral neuropathy; two patients with mononeuritis multiplex; one patient each with meralgia paresthetica, peroneal neuropathy, and cauda equina syndrome; and five indeterminate cases in whom active denervation was limited to paraspinal muscles alone.

\section{Predictive variables}

Table 1 summarizes the presenting symptoms and signs in our study population. For both cervical and lumbosacral referrals, the most prevalent symptom was any radiating neck or back pain (including both dermatomal and non-dermatomal pain). The 
Table 2: Symptoms predictive of cervical radiculopathy $(\mathrm{N}=77)$

\begin{tabular}{|c|c|c|c|c|c|}
\hline Clinical Features & Sensitivity (95\% CI) & Specificity (95\% CI) & PPV (95\% CI) & NPV (95\% CI) & Accuracy \\
\hline \multicolumn{6}{|l|}{ Single component } \\
\hline Radiating neck pain & $54 \%(37-71 \%)$ & $30 \%(22-38 \%)$ & $26 \%(18-34 \%)$ & $59 \%(44-75 \%)$ & $38 \%$ \\
\hline Abnormal dermatomal sensation & $50 \%(32-68 \%)$ & $42 \%(34-50 \%)$ & $28 \%(18-38 \%)$ & $65 \%(52-77 \%)$ & $44 \%$ \\
\hline Arm pain & $75 \%(60-88 \%)$ & $17 \%(10-23 \%)$ & $29 \%(23-34 \%)$ & $60 \%(35-81 \%)$ & $35 \%$ \\
\hline \multicolumn{6}{|l|}{ Two components } \\
\hline Neck pain \& abnormal sensation & $29 \%(14-47 \%)$ & $62 \%(56-71 \%)$ & $26 \%(13-42 \%)$ & $66 \%(59-75 \%)$ & $52 \%$ \\
\hline Neck pain \& arm pain & $46 \%(29-64 \%)$ & $43 \%(36-52 \%)$ & $27 \%(17-37 \%)$ & $64 \%(2-76 \%)$ & $44 \%$ \\
\hline Abnormal sensation $\&$ arm pain & $42 \%(25-60 \%)$ & $59 \%(51-67 \%)$ & $31 \%(18-45 \%)$ & $69 \%(60-79 \%)$ & $53 \%$ \\
\hline \multicolumn{6}{|l|}{ All three components } \\
\hline $\begin{array}{l}\text { Neck pain, arm pain \& abnormal } \\
\text { sensation }\end{array}$ & $29 \%(15-46 \%)$ & $76 \%(69-83 \%)$ & $35 \%(17-55 \%)$ & $70 \%(64-77 \%)$ & $61 \%$ \\
\hline
\end{tabular}

CI, confidence interval; PPV, positive predictive value; NPV, negative predictive value

Table 3: Signs predictive of cervical radiculopathy $(\mathrm{N}=77)$

\begin{tabular}{lcccc}
\hline Clinical Features & Sensitivity (95\% CI) & Specificity (95\% CI) & PPV (95\% CI) & NPV (95\% CI) \\
\hline Single component & & & Accuracy \\
Dermatomal Sensory loss & $25 \%(12-38 \%)$ & $89 \%(83-95 \%)$ & $50 \%(24-76 \%)$ & $72 \%(67-77 \%)$ \\
Segmental reflex loss & $22 \%(11-27 \%)$ & $97 \%(92-99 \%)$ & $79 \%(37-97 \%)$ & $73 \%(69-75 \%)$ \\
Myotomal weakness & $54 \%(38-65 \%)$ & $93 \%(85-97 \%)$ & $77 \%(53-92 \%)$ & $82 \%(75-86 \%)$ \\
Two components & & & & $79 \%$ \\
Sensory loss \& reflex loss & $14 \%(5-16 \%)$ & $99 \%(94-100 \%)$ & $88 \%(31-100 \%)$ & $71 \%(68-72 \%)$ \\
Sensory loss \& weakness & $21 \%(9-28 \%)$ & $96 \%(91-99 \%)$ & $71 \%(32-95 \%)$ & $73 \%(69-75 \%)$ \\
Reflex loss \& weakness & $22 \%(11-24 \%)$ & $99 \%(94-100 \%)$ & $92 \%(45-100 \%)$ & $73 \%(69-74 \%)$ \\
All three components & & & $73 \%$ & $75 \%$ \\
Sensory loss, reflex loss \& & $14 \%(5-16 \%)$ & $99 \%(95-100 \%)$ & $87 \%(31-100 \%)$ & $71 \%(68-72 \%)$ \\
weakness & & & $72 \%$ \\
\hline
\end{tabular}

CI, confidence interval; PPV, positive predictive value; NPV, negative predictive value

Table 4: Symptoms predictive of lumbosacral radiculopathy $(\mathrm{N}=123)$

\begin{tabular}{|c|c|c|c|c|c|}
\hline Clinical Features & Sensitivity (95\% C.I) & Specificity (95\% C.I) & PPV (95\% C.I) & NPV (95\% C.I) & Accuracy \\
\hline \multicolumn{6}{|l|}{ Single component } \\
\hline $\begin{array}{l}\text { Radiating back pain } \\
\text { Abnormal dermatomal sensation } \\
\text { Leg pain }\end{array}$ & $\begin{array}{l}58 \%(51-66 \%) \\
49 \%(42-57 \%) \\
73 \%(67-79 \%)\end{array}$ & $\begin{array}{l}44 \%(32-56 \%) \\
48 \%(36-60 \%) \\
26 \%(16-37 \%)\end{array}$ & $\begin{array}{l}63 \%(56-71 \%) \\
61 \%(52-70 \%) \\
62 \%(57-68 \%)\end{array}$ & $\begin{array}{l}39 \%(28-49 \%) \\
36 \%(27-45 \%) \\
36 \%(22-52 \%)\end{array}$ & $\begin{array}{l}53 \% \\
49 \% \\
55 \%\end{array}$ \\
\hline \multicolumn{6}{|l|}{$\underline{\text { Two components }}$} \\
\hline $\begin{array}{l}\text { Back pain \& abnormal sensation } \\
\text { Back pain \& leg pain } \\
\text { Abnormal sensation \& leg pain }\end{array}$ & $\begin{array}{l}29 \%(22-35 \%) \\
51 \%(43-58 \%) \\
36 \%(29-43 \%)\end{array}$ & $\begin{array}{c}72 \%(60-82) \\
50 \%(38-62 \%) \\
70 \%(57-80 \%)\end{array}$ & $\begin{array}{c}63 \%(48-77 \%) \\
63 \%(54-72) \\
67 \%(53-78 \%)\end{array}$ & $\begin{array}{l}38 \%(32-43 \%) \\
38 \%(29-47 \%) \\
39 \%(33-46 \%)\end{array}$ & $\begin{array}{l}45 \% \\
50 \% \\
49 \%\end{array}$ \\
\hline $\begin{array}{l}\text { All three components } \\
\text { Back pain, abnormal sensation \& } \\
\text { leg pain }\end{array}$ & $26 \%(19-32 \%)$ & $78 \%(67-88 \%)$ & $67 \%(50-81 \%)$ & $39 \%(33-43 \%)$ & $46 \%$ \\
\hline
\end{tabular}

$\mathrm{CI}$, confidence interval; PPV, positive predictive value; NPV, negative predictive value 
Table 5: Signs predictive of lumbosacral radiculopathy $(\mathrm{N}=123)$

\begin{tabular}{|c|c|c|c|c|c|}
\hline Clinical Features & Sensitivity (95\% CI) & Specificity $(95 \%$ CI) & PPV (95\% CI) & NPV (95\% CI) & Accuracy \\
\hline \multicolumn{6}{|l|}{ Single component } \\
\hline Dermatomal sensory loss & $33 \%(26-38 \%)$ & $80 \%(69-89 \%)$ & $74 \%(58-86 \%)$ & $42 \%(36-46 \%)$ & $50 \%$ \\
\hline Segmental reflex loss & $57 \%(50-63 \%)$ & $74 \%(62-84 \%)$ & $79 \%(69-87 \%)$ & $51 \%(42-58 \%)$ & $63 \%$ \\
\hline Myotomal weakness & $31 \%(26-32 \%)$ & $98 \%(90-100 \%)$ & $98 \%(82-100 \%)$ & $46 \%(43-48 \%)$ & $57 \%$ \\
\hline Positive SLR test & $31 \%(25-35 \%)$ & $89 \%(79-96 \%)$ & $83 \%(66-93 \%)$ & $44 \%(38-47 \%)$ & $53 \%$ \\
\hline \multicolumn{6}{|l|}{ Two components } \\
\hline$\overline{\text { Sensory loss \& reflex loss }}$ & $14 \%(9-18 \%)$ & $91 \%(83-97 \%)$ & $73 \%(47-91 \%)$ & $39 \%(35-41 \%)$ & $43 \%$ \\
\hline Sensory loss \& weakness & $14 \%(9-14 \%)$ & $99 \%(91-100 \%)$ & $96 \%(64-100 \%)$ & $41 \%(38-41 \%)$ & $46 \%$ \\
\hline Sensory loss \& positive SLR & $17 \%(11-20 \%)$ & $91 \%(82-97 \%)$ & $76 \%(52-92 \%)$ & $40 \%(36-42 \%)$ & $45 \%$ \\
\hline Reflex loss \& weakness & $21 \%(16-22 \%)$ & $98 \%(91-100 \%)$ & $97 \%(75-100 \%)$ & $43 \%(39-43 \%)$ & $50 \%$ \\
\hline Reflex loss \& positive SLR & $17 \%(12-20 \%)$ & $94 \%(85-98 \%)$ & $81 \%(56-95 \%)$ & $40 \%(36-42 \%)$ & $46 \%$ \\
\hline Weakness \& positive SLR & $12 \%(8-13 \%)$ & $98 \%(92-100 \%)$ & $95 \%(61-100 \%)$ & $40 \%(38-41 \%)$ & $45 \%$ \\
\hline \multicolumn{6}{|l|}{ All four components } \\
\hline $\begin{array}{l}\text { Sensory loss, reflex loss, } \\
\text { weakness \& positive SLR }\end{array}$ & $3 \%(1-4 \%)$ & $98 \%(95-100 \%)$ & $83 \%(21-100 \%)$ & $38 \%(37-39 \%)$ & $39 \%$ \\
\hline
\end{tabular}

SLR, straight-leg raising; CI, confidence interval; PPV, positive predictive value; NPV, negative predictive value

most prevalent sign was myotomal weakness in cervical referrals, and segmental reflex loss in lumbosacral referrals.

Tables 2-5 show statistical measures of the ability of symptoms and signs to predict EMG-confirmed radiculopathy. For both cervical and lumbosacral referrals, dermatomal pain was the most sensitive individual symptom predicting root disease. Segmental reflex loss and myotomal weakness were the most specific signs predicting cervical root disease, while myotomal weakness and positive straight-leg raising test were the most specific signs predicting lumbosacral root disease. For both cervical and lumbosacral cases, the presence of dermatomal sensory loss in combination with segmental reflex loss and myotomal weakness approached a specificity of $99 \%$. Across all cases, myotomal weakness and segmental reflex loss emerged as the most accurate predictors of root disease.

\section{DisCuSSION}

The value of history and physical examination in predicting the presence of radiculopathy varies depending on the diagnostic approach. Electrodiagnosis and magnetic resonance imaging (MRI) are the two confirmatory techniques, albeit qualitatively distinct and with different yields. Despite its discomfort and semi-invasive nature, electrodiagnosis is irreplaceable for clinical decision-making in this setting. In this paper, we have focused on the particular correlation of clinical variables with electrodiagnostic yield in radiculopathy, in the hopes of refining patient selection and minimizing unnecessary testing.

Validation for the role of electrodiagnosis comes from agreement between the results of EMG and magnetic resonance imaging (MRI), as well as a predictive relationship between EMG findings and post-operative outcome. In a majority of patients, EMG abnormalities show concordance with findings on imaging. For example, Nardin and colleagues found $60 \%$ agreement in EMG and MRI abnormalities in 47 cases of suspected cervical or lumbosacral radiculopathy ${ }^{12}$. In another study, active denervation on EMG predicted MRI evidence of radiculopathy with an odds ratio of $4.5^{13}$. The two modalities provide different kinds of information (structural versus functional) and in standard clinical practice are used as complementary investigations. Although the false-positive rate for MRI is significant, the false-positive rate for EMG may be lower. A study by Jensen et al found disc abnormalities on MRI in up to $53 \%$ of asymptomatic individuals ${ }^{14}$; in contrast, a consensus statement by the American Association of Neuromuscular and Electrodiagnostic Medicine noted moderate sensitivity (50-71\%) and high specificity (65-85\%) for needle EMG in the diagnosis of radiculopathy ${ }^{15}$. An EMG may be particularly useful in symptomatic cases where imaging is equivocal or negative ${ }^{16}$. The ability of EMG to predict success after surgical intervention further validates the role of electrodiagnosis. A study of 20 patients undergoing anterior cervical interbody fusion for suspected cervical radiculopathy found that pre-operative EMG abnormalities (observed in 8 patients) predicted a better post-operative outcome with high statistical significance $^{14}$.

The predictive correlation of symptoms and signs with EMG evidence of radiculopathy has been understudied. In a comprehensive synthesis, Lauder identified ten studies of suspected lumbosacral radiculopathy and thirteen studies of suspected cervical radiculopathy in which clinical parameters were correlated with diagnostic yield ${ }^{17}$; in most cases, however, the gold standard was surgical confirmation rather than electrodiagnosis. In a subsequent report, Wainner et al compared clinical variables with electrophysiological results in patients with suspected cervical radiculopathy and found that two-thirds of 34 clinical items were rated as fair or better ${ }^{18}$; symptoms in this study were elicited through a self-reported questionnaire rather than clinical history-taking, and examination findings 
were assessed by physical therapists. The role of physical examination in selecting patients with suspected lumbosacral disc herniation for imaging and possible surgery was addressed in a recent Cochrane review; the authors concluded that physical examination has "poor diagnostic performance" in this setting, although better performance may be obtained when clinical examination items are combined ${ }^{19}$.

Our literature search yielded two studies similar to ours that rigorously assessed clinical predictors of EMG-confirmed radiculopathy - a study of 170 cases of suspected lumbosacral radiculopathy ${ }^{20}$, and another study of 183 cases of suspected cervical radiculopathy ${ }^{21}$. Patient demographics in these studies were similar to our study sample. In both reports, symptoms including pain and weakness were found to be more sensitive than specific, while abnormalities on examination were more specific than sensitive. Dermatomal pain was the most sensitive symptom and myotomal weakness the most specific physical abnormality, which is in agreement with our observations. Similar conclusions have emerged when comparing clinical predictors with MRI. In a study of 202 patients addressing this question in suspected lumbosacral radiculopathy, Coster et al found dermatomal pain, myotomal weakness, and abnormal SLR to be the strongest predictors of MRI-positive radiculopathy ${ }^{13}$.

The relevance of our results for patient selection and referral lies in the ability of clinical findings to predict positive and negative results, which is indicated by positive and negative predictive values and by the composite measure of accuracy. The negative predictive value (NPV) is of particular interest in this regard, as it conveys the likelihood of conducting a negative test that could have been avoided. The highest NPV for any single item in our study was $82 \%$ (95\% CI: $75-86 \%$ ), for cervical myotomal weakness; this suggests that even in the absence of weakness, EMG can be diagnostic in up to $14-25 \%$ patients with suspected cervical radiculopathy. The NPV was significantly lower for all symptoms and signs in the lumbosacral region, with the highest value of $51 \%$ (95\% CI: 42-58\%) observed for segmental reflex loss; this suggests that even in the absence of a dropped reflex, EMG can be diagnostic in up to $42-58 \%$ patients with suspected lumbosacral radiculopathy. Overall, while the presence of dermatomal pain, myotomal weakness or segmental reflex loss increases the likelihood of a positive electrodiagnostic study, their absence is not accurate enough to avoid an EMG study if it is indicated on other grounds. Our study does not negate the status of EMG as one of the mainstays of radiculopathy diagnosis.

\section{REFERENCES}

1. Mixter W, Barr J. Rupture of the intervertebral disc with involvement of the spinal canal. N Engl J Med. 1934;211:210-4.

2. Tarulli AW, Raynor EM. Lumbosacral radiculopathy. Neurol Clin. 2007;25:387-405.

3. Roth D, Mukai A, Thomas P, Hudgins TH, Alleva JT. Cervical radiculopathy. Dis Mon. 2009;55:737-56.

4. Wilbourn AJ, Aminoff MJ. AAEM minimonograph 32: the electrodiagnostic examination in patients with radiculopathies. Muscle Nerve. 1998;21:1612-31.

5. American Association of Electrodiagnostic Medicine, So YT. Guidelines in electrodiagnostic medicine. Practice parameter for needle electromyographic evaluation of patients with suspected cervical radiculopathy. Muscle Nerve. 1999;Suppl:S209-21.

6. Cho SC, Ferrante MA, Levin KH, Harmon RL, So YT. Utility of electrodiagnostic testing in evaluating patients with lumbosacral radiculopathy: an evidence-based review. Muscle Nerve. 2010;42:276-82.

7. Fuller G. How to get the most out of nerve conduction studies and electromyography. J Neurol Neurosurg Psychiatry. 2005;76 Suppl II:ii41-6.

8. Levin KH, Maggiano HJ, Wilbourn AJ. Cervical radiculopathies: comparison of surgical and EMG localization of single root lesions. Neurology. 1996;46:1022-5.

9. Lauder TD, Dillingham TR, Huston CW, Chang AS, Belandres PV. Lumbosacral radiculopathy screen. Optimizing the number of muscles studies. Am J Phys Med Rehabil. 1994;73:394-402.

10. Radhakrishnan K, Litchy WJ, O'Fallon WM, Kurland LT. Epidemiology of cervical radiculopathy. A population-based study from Rochester, Minnesota, 1976 through 1990. Brain. 1994;117:325-35.

11. Porta M, editor. A Dictionary of Epidemiology. 5th ed. New York: Oxford University Press; 2008.

12. Nardin RA, Patel MR, Gudas TF, Rutkove SB, Raynor EM. Electromyography and magnetic resonance imaging in the evaluation of radiculopathy. Muscle Nerve. 1999;22:151-5.

13. Coster S, de Bruijn SFTM, Tavy DLJ. Diagnostic value of history, physical examination and needle electromyography in diagnosing lumbosacral radiculopathy. J Neurol. 2010;257: 332-7.

14. Jensen MC, Brant-Zawadski MN, Obuchowski N, Modic MT, Malkasian D, Ross JS. Magnetic resonance imaging of the spine in people without back pain. N Engl J Med. 1994;331:69-73.

15. Robinson LR. Electromyography, magnetic resonance imaging, and radiculopathy: it's time to focus on specificity. Muscle Nerve. 1999;22:149-50.

16. Alrawi MF, Khalil NM, Mitchell P, Hughes SP. The value of neurophysiological and imaging studies in predicting outcome in the surgical treatment of cervical radiculopathy. Eur Spine J. 2007; 16:495-500.

17. Lauder TD. Physical examination signs, clinical symptoms, and their relationship to electrodiagnostic findings and the presence of radiculopathy. Phys Med Rehabil Clin N Am. 2002;13: 451-67.

18. Wainner RS, Fritz JM, Irrgang JJ, Boninger ML, Delitto A, Allison S. Reliability and diagnostic accuracy of the clinical examination and patient self-report measures for cervical radiculopathy. Spine. 2003;28:52-62.

19. van der Windt DA, Simons E, Piphagen II, et al. Physical examination for lumbar radiculopathy due to disc herniation in patients with low-back pain. Cochrane Database Syst Rev. 2010;2:CD007431.

20. Lauder TD, Dillingham TR, Andary M, et al. Effect of history and exam in predicting electrodiagnostic outcome among patients with suspected lumbosacral radiculopathy. Am J Phys Med Rehabil. 2000;79:60-8.

21. Lauder TD, Dillingham TR, Andary $M$, et al. Predicting electrodiagnostic outcome in patients with upper limb symptoms: are the history and physical examination helpful? Arch Phys Med Rehabil. 2000;81:436-41. 